\title{
INFORMACIONES
}





\section{Renovación del Comité Científico de Daimon Revista Internacional de Filosofía}

El pasado 26 de febrero de 2014, el Departamento de Filosofía de la Universidad de Murcia, editor de Daimon. Revista Internacional de Filosofía acordó renovar el Comité Científico de la revista, a propuesta de su Consejo Editorial.

A partir de ahora, el Comité Científico de Daimon no tendrá un carácter permanente y meramente honorífico, sino que será renovado cada tres años, conforme a los criterios que figuran más abajo, con los que se pretende reconocer el trabajo efectivo de las personas que colaboran asiduamente con la revista. Serán miembros del Comité Científico los colaboradores que cumplan al menos uno de los siguientes criterios:

1. Antiguos miembros del Comité Editorial.

2. Editores de algún número monográfico.

3. Revisores residentes en el extranjero que hayan realizado al menos la revisión de un artículo en los últimos tres años.

4. Revisores residentes en España que hayan realizado cinco o más revisiones de artículos en los últimos tres años.

En aplicación de estos nuevos criterios, y conforme a los datos que obran en nuestro poder, hemos procedido a renovar el Comité Científico de la revista para los próximos tres años, tal como podrá comprobarse en los créditos que figuran al inicio de la publicación.

Las funciones encomendadas al Comité Científico son las siguientes:

- Evaluar trabajos enviados a la revista para ser publicados.

- Proponer a los Editores Asociados nombres de nuevos evaluadores competentes en el ámbito internacional para revisar originales en los temas de su especialidad.

- Asesorar al Comité Editorial para mejorar el funcionamiento de la revista en todos los aspectos (edición, distribución, visibilidad, etc.).

Los miembros del Consejo Editorial queremos agradecer muy sinceramente a los anteriores miembros del Comité Científico el apoyo que nos han brindado en los años precedentes y nos gustaría seguir contando con su colaboración en los próximos números de Daimon, con la consiguiente posibilidad de volver a pertenecer al Comité Científico. También agradecemos a los nuevos miembros su disponibilidad para seguir apoyando a la revista y potenciar su presencia y visibilidad como revista de alta calidad internacionalmente reconocida. 
